\title{
RELATIONSHIP BETWEEN THE QUALITY OF LIFE AND PHYSICAL ACTIVITY IN PATIENTS WITH DEPRESSION DISORDER
}

\author{
Aistė Leleikienė, Jūratė Požèrienė, Diana Rẻklaitienė \\ Lithuanian Sports University, Kaunas, Lithuania
}

\begin{abstract}
Background. Positive effect of physical activity on mental health has been proven by scientific research, whereas the quality of life scale is an important instrument for the assessment of the overall functioning of people with mental disorders. The aim of the study was to determine the relationship between the quality of life and physical activity in patients with depressive disorder.

Methods. The survey involved randomly selected subjects $(n=38)$ with depression aged 20-75. The subjects were assessed using quality of life SF-36 and physical activity questionnaires.

Results. The survey results showed that patients with mental disorders evaluated their physical health much better than mental health $(p<.01)$. General health perception and social functioning improve with increasing energy and vitality. Subjects who were more physically active at home rated their general physical activity better in quality of life questionnaire.

Conclusions. Higher physical activity at work has a positive influence on vitality and general health perception.
\end{abstract}

Keywords: quality of life, physical activity, mental health.

\section{INTRODUCTION}

$\mathrm{P}$ aradigms in the assessment of human health have been changing for decades. Human health is currently defined as a state of complete physical, mental and social well-being, rather than the mere absence of disease or illness (WHO, 2015). Nowadays patients' evaluation of their health condition is becoming more and more important and depends not only on clinician's report of the illness (Bullinger \& Quitmann, 2014). One of the elements of this perspective of health is quality of life. During last decades improving the quality of life (QoL) has been increasingly acknowledged as an important health index of individuals, social groups and even the entire society; and has garnered greater attention in both clinical practice and research (Reklaitiene, Karpaviciute, \& Pozeriene, 2010; Revicki, Kleinman, \& Cella, 2014).

Health as QoL component has become an important physical and social factor that was included into Human Development Index (Chaaban, Irani, \& Khoury, 2016; Crafts, 1997; Niels, 2004). However, there has been a shift in mental health service policy from an emphasis on treatment focused on reducing symptoms, based on a narrow notion of pathology and illness, to a more holistic approach which takes into consideration well-being, recovery, social functioning, and QoL (Hogan, 2003). A policy that more people attending mental health services will recover and have a good quality of life necessitates that appropriate outcome measures are in place (Connell, O'Cathain, \& Brazier, 2014).

Studies that evaluate QoL in persons with mental disorders are rather recent (Katschnig, 2006; Revicki et al., 2014). QoL has become the main instrument of measuring the success of treatment of mental disorders. Patients with serious mental disorders have a much lower QoL compared to the general population (Xiang, Chiu, \& Ungvari, 
2010). QoL is presented as direct outcome of mental illness, i.e. better QoL can improve the level of mental functions (Jakovljević, 2006).

Recently intensive research into the influence of physical activity on mental health has been conducted, however positive influence of physical activity on physical health was found long time ago (Goodwin, 2003; Harvey, Hotopf, Overland, \& Mykletun, 2010; Wiles, Haase, Gallacher, Lawlor, $\&$ Lewis, 2007). Systemic analyses of subjects and interventions have revealed a relationship between physical activity and depression: physical activity reduces the possibility to experience symptoms of depression or even to suffer from depression (Brown, Ford, Burton, Marshall, \& Dobson, 2005; Herring, O'Connor, \& Dishman, 2010; Saxena, Van Ommeren, Tang, \& Armstrong, 2005). Unfortunately, many depressed and anxious individuals either receive inadequate treatment or none whatsoever, and the capacity for treatment falls short of the need. Substantial mental health gains may be achieved by improving a habit of regular exercise, and the potentials of exercise may be integrated with cognitive-behavioural theory in daily practice (Martisen, 2008). It should be noted that a few researchers have investigated the hypothesis of reciprocal relationship between physical activity and symptoms of depression and anxiety, i.e. that symptoms of depression and anxiety can influence physical activity (Roshanaei Moghaddam, Katon, \& Russo, 2009).

Mason and Holt (2012) presented the main findings from their review of studies that explored the experiences of physical activity among mental health service users: an opportunity for social interaction and social support; a sense of meaning, purpose, and achievement; feeling safe; improved symptoms; and identity. Similar findings were obtained by Crone and Guy (2008), who pointed out the health gains from exercise, such as getting control over one's life, having facilities for social life, and improving well-being. The evaluation of experiences among forensic mental health patients participating in an exercise program illustrated the importance of exercise: managing anxiety and stress; providing meaning and structure to the day; forming new relationships; learning new skills; and creating partnerships in care (Wynaden, Barr, Omari, \& Fulton, 2012). Thus, the aim of our study was to determine the relationship between the QoL and physical activity in patients with mental health disorders. The hypothesis of the study was as follows: the quality of life of patients with depression disorder directly depends on physical activity: higher physical activity leads to better quality of life.

\section{METHODS}

Participants. In order to be eligible to participate in this study several inclusion criteria were applied: (1) having mental health disorders, as defined for this study, is a condition that causes a person difficulty in performing activities in important areas of life, where the difficulties are a consequence of mental disorder; (2) able to complete the questionnaire i.e. no substantial learning disability or dementia and no severe disability such as blindness or extreme frailty precluding the ability to answer independently.

Participants were recruited from Keddainiai Mental Health Centre and expressed interest in the study. We selected 54 participants who were diagnosed with depressive disorder and 38 randomly were selected and agreed to participate in the study after familiarization with the research protocol. All participants $(n=38)$ were interviewed by the health researcher with a background in medical sciences. The age of the participants ranged from 20 to 75 , $($ mean $=54.1 \pm 18.3) ; 68.4 \%$ $(n=26)$ of the subjects were females, $31.6 \%(n=$ 12) were males. The majority of participants, i.e. $55.3 \%(n=21)$ were single (unmarried, divorced, widowed). A bigger part of the subjects, i.e. $52.6 \%$ $(n=20)$ were unemployed. Most of them were city dwellers $-81.6 \%(n=31)$.

Data collection. The QoL of patients with depression disorder was investigated by using a Short Form Health Survey (SF-36). The survey is a brief and easily administered measure of healthrelated QoL and consists of 36 multiple-choice items assessing 8 domains: physical functioning, role limitations due to physical and emotional problems, social functioning, mental health (emotional well-being), vitality/energy; bodily pain, and general health. Scores for each domain range from 0 to 100 . Higher scores represent better health perceptions. Summary of physical health component (physical functioning, role limitations due to physical problems, bodily pain and general health perception) and mental component (vitality, social functioning, role limitations due to emotional problems and mental health) were computed too. The survey SF-36 was adapted to Lithuanian population and reliability and validity study has been conducted (Rugienè, Dadonienè, 
\& Venalis, 2005). In this study, the Cronbach's alpha coefficient for SF-36 was .78 (good). Also Cronbach's alpha coefficient was calculated for the eight subscales (from .67 to .94).

Physical activity was assessed by modified Baecke habitual physical activity questionnaire (BHPAQ) (Baecke, Burema, \& Friters, 1982). This questionnaire is a self-administered questionnaire that was used to objectively assess habitual physical activity of individuals. The questionnaire examines: (1) Work activities (physical activity level based on occupation, frequency of sitting, standing, walking, lifting, sweating, etc. at work); (2) Sports activity (activity level based on frequency of sweating while engaging in sport, leisure time sporting activity, duration of sporting activity, etc.); (3) Leisure activity (activity level based on duration of watching television, walking, cycling, etc. during leisure activities). All items result in a separate score that incorporates activity duration, frequency, and an intensity code based on energy costs. Summing the household score, sport score, and leisure time activity score results in a continuous overall produces the activity score. The questionnaire was administered as a face to face interview by an experienced research assistant.

Kaunas regional biomedical research ethics committee (BE-2-18) approved the study. Participants were informed orally and in writing about the aim of the study, that participation was voluntary and confidential. Informed consent was obtained from all participants. All participants were adults and capable to give written consent, but also written informed consent from next of kin of the patients was obtained.

Statistical analysis. Data analyses were performed using SPSS 16.0 (Statistical Package for Social Sciences for Windows). Baseline characteristics were expressed as real numbers (per cent) and mean $\pm S D$. Data of QoL domains were compared using dependent $t$-test. The associations between QoL domains and physical activity were tested by Spearmen's correlation. Statistical significance was assessed at the levels of $p<.05$.

\section{RESULTS}

Physical activity at home is rather high among the subjects with depression: $76.9 \%$ of the subjects most often or always do light housework, such as dusting, dishwashing and the like. Only slightly fewer respondents $(71.8 \%)$ most often or always do difficult housework, such as cleaning the floor or window cleaning, taking away garbage and the like; $35.9 \%$ of the subjects cook hot meals more than 5 times a week, and only $5.1 \%$ of the subjects never cook hot meals at home. The same percentage of subjects never or less than once a week go shopping; $46.2 \%$ of the subjects go shopping by car. Even one-fifth of the subjects $(20.5 \%)$ never climb the stairs.

Daily physical activities assessment results show that quite a big part of the subjects $-69.2 \%$ climb stairs instead of taking a lift in order to exercise and even $84.6 \%$ of the subjects walk short distances instead of going by bus or in a car. However, fewer respondents park their cars further from the destination point and walk the remaining distance or go for a walk during lunch break after dinner or get off the bus earlier in order to walk the remaining distance.

The survey results revealed low regular physical activity among the subjects. Brisk walking or running at least $2 \mathrm{~km}$ a week was slightly more popular among the respondents with mental disorders $(38.5 \%)$; cycling being in the second place. Even $23.1 \%$ of respondents indicated that during the last 3 months they cycled at least $20 \mathrm{~km}$ per week. Less than $10 \%$ of the respondents were engaged in other physical activities (sports games, such as table tennis, tennis, basketball, football, swimming).

The subjects involved in the survey evaluated the quality of life below average $(44.6 \pm 15.7)$. The analysis of health related section of quality of life questionnaire revealed that mentally ill respondents gave the highest scores in physical activity domain (68.2 \pm 29.6$)$, and the lowest scores in social functioning domain $(35.1 \pm 24.8)(p<$ .001). Presumably, mental disorders of respondents have a negative effect on their emotional conditions, vitality, social functioning in the society and, therefore, low QoL. The respondents rated their mental health significantly lower, i.e. there was a statistically significant difference between physical and mental health component averages $(p<.001)$.

Males with depression rated QoL in health related domains slightly better than females (Table 1). The biggest differences between males and females are seen in the following QoL domains: emotional health $(47.33 \pm 19.4$ and $40.8 \pm$ $19.3)$, vitality (44.6 \pm 23.6 and $33.2 \pm 20.9)$, physical activity (77.1 \pm 25.8 and $64.2 \pm 30.7)$, although these differences are statistically insignificant.

The analysis of the influence of family status on QoL in patients with mental disorders showed that 
Table 1. Scores of SF-36 questionnaire components in terms of sex and family status

\begin{tabular}{|c|c|c|c|c|c|c|c|c|c|c|c|c|}
\hline \multirow{3}{*}{\begin{tabular}{|l|}
\multicolumn{1}{|c|}{ Mean score } \\
$\begin{array}{l}\text { SF-36 questionnaire } \\
\text { components: }\end{array}$ \\
\end{tabular}} & & & \multicolumn{4}{|c|}{ Sex } & \multicolumn{6}{|c|}{ Family status } \\
\hline & \multicolumn{2}{|c|}{ Mean score } & \multicolumn{2}{|c|}{ Male } & \multicolumn{2}{|c|}{ Female } & \multicolumn{2}{|c|}{ Single } & \multicolumn{2}{|c|}{ Divorced } & \multicolumn{2}{|c|}{ Married } \\
\hline & mean & $S D$ & mean & $S D$ & mean & $S D$ & mean & $S D$ & mean & $S D$ & mean & $S D$ \\
\hline $\begin{array}{l}\text { General mental health } \\
\text { component }\end{array}$ & 31.60 & 12.51 & 35.1 & 15.3 & 30.1 & 11.0 & $24.4^{*}$ & 8.1 & 37.4 & 16.9 & $32.9 *$ & 11.7 \\
\hline $\begin{array}{l}\text { General physical health } \\
\text { component }\end{array}$ & 41.31 & 10.53 & 44.6 & 39.8 & 39.8 & 11.3 & 44.2 & 6.3 & 39.4 & 6.1 & 41 & 14.2 \\
\hline Emotional health & 42.83 & 19.31 & 47.33 & 19.4 & 40.8 & 19.3 & 34.9 & 19.5 & 43.5 & 18.9 & 46.1 & 20.2 \\
\hline $\begin{array}{l}\text { Role limitations due to } \\
\text { emotional problems }\end{array}$ & 35.34 & 35.04 & 38.9 & 34.3 & 33.8 & 35.8 & $18.2 *$ & 27.3 & $45.9 *$ & 39.6 & $41.9 *$ & 36.3 \\
\hline Social functioning & $35.05 *$ & 24.84 & 35.4 & 28.1 & 34.9 & 23.8 & $22.7 *$ & 19.2 & 34.4 & 17.4 & $42.9 *$ & 29.5 \\
\hline Vitality and energy & 36.69 & 22.10 & 44.6 & 23.6 & 33.2 & 20.9 & 30.5 & 24.2 & 37.5 & 18.7 & 41 & 23.1 \\
\hline $\begin{array}{l}\text { General health } \\
\text { perception }\end{array}$ & 44.41 & 17.61 & 48.8 & 21.1 & 42.4 & 20.9 & 42.6 & 20.4 & 48.4 & 20.1 & 43.9 & 17.0 \\
\hline Bodily pain & 47.92 & 28.42 & 51.8 & 32.9 & 46.2 & 26.6 & 46.4 & 27.9 & $27.8^{*}$ & 13.7 & $59.6 *$ & 31.2 \\
\hline $\begin{array}{l}\text { Role limitations due to } \\
\text { physical problems }\end{array}$ & 46.11 & 33.73 & 45.8 & 35.1 & 46.4 & 33.8 & 43.2 & 35.5 & 50 & 35.3 & 44.1 & 36.0 \\
\hline Physical functioning & $68.19 *$ & 29.61 & 77.1 & 25.8 & 64.2 & 30.8 & 70.5 & 30.8 & 64.3 & 21.1 & 72.6 & 31.6 \\
\hline
\end{tabular}

Note. *statistically significant difference of indicators, $p<.05$.

subjects who lived not alone (with the family) gave significantly higher scores in social functioning scale $(42.9 \pm 29.5)$ and general health perception scale $(32.9 \pm 11.8)$ compared to the scores of those living alone: social functioning $(22.7 \pm 19.2)$ and general mental health $(24.4 \pm 8.1)(p<.05)$ (Table $1)$. The survey revealed that single patients with mental disorders experienced many more role limitations due to emotional health $(18.2 \pm 27.3)$ than married $(41.9 \pm 36.3)$ or divorced $(45.9 \pm$ $39.6)$ patients $(p<.05)$. Divorced respondents with mental disorders experienced more pain $(27.7 \pm$ 13.7) than married subjects $(59.60 \pm 31.2)(p<.05)$.

The analysis of the survey data showed the existing relationship of QoL domains (components) (Table 2). Strong statistically significant relations were established between the following QoL domains: vitality and general health perception $(r=.750, p<.01)$ and social functioning $(r=.709$, $p<.01)$.
Average statistically significant relations: better general mental health perception was influenced by better emotional health $(r=.679, p<.01)$, fewer role restrictions due to emotional health $(r=.655$, $p<.01)$, better social functioning $(r=.697, p<.01)$, higher vitality $(r=.598, p<.01)$. Physical activity has a positive effect on the general physical health component $(r=.617, p<.01)$, better emotional health has a positive effect on social functioning $(r=.633, p<.01)$, vitality $(r=.691, p<.01)$ and general health perception $(r=.564, p<.01)$.

The analysis of QoL and physical activity relations showed statistically significant relationship between physical activity at work and health perception "now". The less time the respondents spend at work sitting, the better they perceive their general health $(r=.421, p<$ .01). Although the respondents indicated high physical activity at home and at work, statistically significant correlations were observed only 
Table 2. Relationship between the quality of life domains

\begin{tabular}{|c|c|c|c|c|c|c|c|c|c|}
\hline $\begin{array}{c}\text { Spearmen's correlation } \\
\text { coefficient }\end{array}$ & GMHC & GPHC & EK & RLEH & SF & V & GHP & $\mathbf{P}$ & RLPH \\
\hline GPHC & -0.236 & & & & & & & & \\
\hline EH & $0.679 * *$ & 0.055 & & & & & & & \\
\hline RLEH & $0.655^{* *}$ & -0.116 & $0.375^{*}$ & & & & & & \\
\hline SF & $0.697 * *$ & -0.013 & $0.633 * *$ & $0.331 *$ & & & & & \\
\hline V & $0.598 * *$ & -0.148 & $0.691 * *$ & 0.252 & $0.709 * *$ & & & & \\
\hline GHP & $0.435^{* *}$ & -0.141 & $0.564 * *$ & 0.194 & $0.435^{* *}$ & $0.750^{* *}$ & & & \\
\hline $\mathbf{P}$ & 0.062 & 0.310 & 0.311 & -0.073 & $0.355^{*}$ & $0.336^{*}$ & 0.258 & & \\
\hline RLPH & 0.172 & 0.306 & $0.320^{*}$ & $0.482 * *$ & 0.160 & 0.074 & 0.066 & 0.010 & \\
\hline PA & -0.159 & $0.617 * *$ & 0.245 & 0.031 & 0.131 & 0.167 & 0.145 & 0.237 & 0.069 \\
\hline
\end{tabular}

Notes. GMHC - General mental health component; GPHC - General physical health component; EH - Emotional health; RLEH-Role limitations due to emotional health; SF - Social functioning; V - Vitality; GHP - general health perception; P - pain; RLPH - Role limitations due to physical health; PA - physical activity. ${ }^{*} p<<.01 ;{ }^{*} p<.05$.

\begin{tabular}{|l|c|c|c|c|}
\hline $\begin{array}{c}\text { Spearmen's correlation } \\
\text { coefficient }\end{array}$ & $\begin{array}{c}\text { Physical activity } \\
(\mathbf{Q o L})\end{array}$ & Vitality & Pain & $\begin{array}{c}\text { General health } \\
\text { perception }\end{array}$ \\
\hline Physical activity at home & $0.332^{*}$ & $0.227^{*}$ & $0.400^{*}$ & 0.249 \\
\hline Daily physical activity & 0.112 & 0.254 & 0.077 & 0.249 \\
\hline Physical activity at work & 0.160 & $0.443^{* *}$ & 0.144 & $0.424 * *$ \\
\hline
\end{tabular}

Table 3. Relationship between QOL domains and physical activity

between physical activity at home (doing simple housework) and general physical activity in quality of life questionnaire. The higher physical activity at home, the higher was the rating of general physical activity in quality of life questionnaire $(r=.332$, $p<.05$ ) (Table 3). Higher physical activity has a positive effect on vitality of the subjects $(r=.443$, $p<.01)$ and general health perception $(r=.424$, $p<.01)$.

\section{DISCUSSION}

QoL can be related to many factors and circumstances: occupation, education, income and financial status, family life, social functioning, stress, health, quality of leisure time, selfperception, meeting individual needs and other (Katschnig, 2006; Reklaitiene et al., 2010). Several researchers pointed out that QoL in patients with mental disorders also depended on the severity of the disease, the main symptoms and the intensity of their expression (Fleury, Grenier, \& Bamvita, 2015). The research showed that males with mental disorders rated QoL in health related domains slightly better than females. Previous studies, however (Lahelma, Martikainen, Rahkonen, \& Silventoinen, 1999; Loge \& Kaasa, 1998) reported that males had rated QoL lower than females.

In summary of QoL data in terms of family status the study showed that patients with mental disorders who were married and lived in a family gave higher scores in almost all scales of QoL questionnaire compared to other subjects. Presumably, family status has a significant influence on QoL and this presumption corresponds to the findings reported by other researchers (Revicki et al., 2014; Szende \& Nemeth, 2003; Vaez, Ekberg, \& Laflamme, 2004). Our study revealed that physical activity of patients with mental disorders was rather high. The respondents were sufficiently 
physically active at work too; however few of them were engaged in regular physical activity. Although the majority of the subjects indicated that they climbed stairs instead of taking the lift and walked short distances, only a small part respondents parked the car further from the destination point and walked the remaining distance, went for a walk or exercised (played sports games, run, swim) in their free time. Similar results were obtained in other studies that assessed sport and recreational physical activity (Crone \& Gui, 2008). In the quality of life questionnaire the subjects gave the highest scores to the physical activity component. Having analysed these results we may presume that patients with mental disorders identify general physical activity with physical activity at home (doing the housework). Presumably, subjects with mental disorders have insufficient information about the possibilities of recreational physical activity and its importance. The analysis of physical activity at work data shows that patients with mental disorders more often have physically difficult and low-paid jobs.

Our results complement those of prior studies of physical activity and health related quality of life. In the Women's Health Australia study, average scores for perceived general health, mental health, and vitality (measured with the Medical Outcomes Study Short Form-36 instrument) increased with increasing physical activity for women in each of three birth cohorts (18-23 years; 50-55 years; 70-75 years) (Brown, Mishra, Lee, \& Bauman, 2000). In a randomized controlled trial of 215 older adults, patients randomized to receive home-based resistance exercise (three times per week for 35 minutes) experienced 15 to $18 \%$ lower physical and overall disability at six-month follow-up (Jette et al., 1999).

The survey data analysis leads to the presumption that physical activity at home and at work has a positive effect on vitality, which in turn improves emotional health, social functioning and general mental health component. The subjects who experience fewer role limitations due to physical health also experience fewer role limitations due to emotional health. The results of the study show that having better emotional health, social functioning, and vitality, patients with mental disorders perceive their general health better. Similar observations were given by other researchers too. Data of the latest epidemiologic studies show that physical activity may reduce the risk of depression or alleviate depression symptoms. Meta-analysis of population study revealed a positive effect of physical activity both on healthy people and people with health problems (Harvey et al., 2010).

In summary of QoL survey of patients with mental disorders we may state that QoL depends in part on physical activity. However, the survey also showed that the subjects subjectively believed they were physically active, although their physical activity was most often related only with physical activity at home or at work. Such belief reveals social exclusion of such persons. Regular physical activity should be recommended as a composite part of social rehabilitation programme for patients with mental disorders.

\section{CONCLUSIONS}

The survey data show that quality of life of patients with depression is average. Males with mental disorders evaluated their QoL slightly higher than females with mental disorders in all scales of quality of life questionnaire. Persons living with families rated their social functioning and general mental health much better than persons living alone. Patients with mental disorders who receive higher monthly income rated QoL better in physical activity. General health perception and vitality domains compared to persons with lower monthly income.

Strong statistically significant relationships between QoL domains show that general health perception and social functioning improve with higher vitality.

QoL of patients with depression partially depends on physical activity at home, activities of daily living and activities at work. Any kind of physical activity is an important part of personal behaviour that improves the quality of life.

Declaration of interest. The authors report no conflicts of interest. The authors alone are responsible for the content and writing of the paper. 


\section{REFERENCES}

Baecke, J. A. H., Burema, J., \& Friters, J. E. R. (1982). A short questionnaire for the measurement of habitual physical activity in epidemiological studies. American Journal of Clinical Nutrition, 36, 936-942. https://doi. org/10.1093/ajcn/36.5.936

Brown, W. J., Ford, J. H., Burton, N. W., Marshall, A. L., \& Dobson, A. J. (2005). Prospective study of physical activity and depressive symptoms in middle-aged women. American Journal of Preventive Medicine, 29(4), 265-272. doi: 10.1016/j.amepre.2005.06.009

Brown, W. J., Mishra, G., Lee, C., \& Bauman, A. (2000). Leisure time physical activity in Australian women: Relationship with well-being and symptoms. Research Quarterly for Exercise and Sport, 71, 206-16. https:// doi.org/10.1080/02701367.2000.10608901

Bullinger, M., \& Quitmann, J. (2014). Quality of life as patient-reported outcomes: Principles of assessment. Dialogues in Clinical Neuroscience, 16, 137-145.

Chaaban, J., Irani, A., \& Khoury, A. (2016). The composite global well-being index (CGWBI): A new multi-dimensional measure of human development. Social Indicators Research, 129(1), 465-487. https:// doi.org/10.1007/s11205-015-1112-5

Connell, J., O'Cathain, A., \& Brazier, J. (2014). Measuring quality of life in mental health: Are we asking the right questions? Social Science \& Medicine, 120, 12-20. https://doi.org/10.1016/j.socscimed.2014.08.026 Crafts, N. F. R. (1997). The human development index and changes in standard of living: Some historical comparisons. European Review of Economic History, 1(3), 299-322. https://doi.org/10.1017/ S1361491697000142

Crone, D., \& Guy, H. (2008). "I know it is only exercise, but to me it is something that keeps me going": A qualitative approach to understanding mental health service users' experiences of sports therapy. International Journal of Mental Health Nursing, 17(3), 197-207. https://doi.org/10.1111/j.1447-0349.2008.00529.x

Fleury, M. J., Grenier, G., \& Bamvita, J. M. (2015). Predictive typology of subjective quality of life among participants with severe mental disorders after a fiveyear follow-up: A longitudinal two-step cluster analysis. Health and Quality of Life Outcomes, 13, 150-161. doi. org/10.1186/s12955-015-0346-x

Goodwin, R. D. (2003). Association between physical activity and mental disorders among adults in the United States. Preventive Medicine, 36(6), 698-703. https://doi. org/10.1016/S0091-7435(03)00042-2

Harvey, S. B., Hotopf, M., Overland, S., \& Mykletun, A. (2010). Physical activity and common mental disorders. British Journal of Psychiatry, 197(5), 357-634. doi:10.1192/bjp.bp.109.075176
Herring, M. P., O'Connor, P. J., \& Dishman, R. K. (2010). The effect of exercise training on anxiety symptoms among patients: a systematic review. Archives of Internal Medicine, 170(4), 321-331. doi:10.1001/ archinternmed.2009.530

Hogan, M. (2003). New freedom commission on mental health, achieving the promise: transforming mental health care in America. Psychiatric Services, 54(11), 1467-1474. https://doi.org/10.1176/appi.ps.54.11.1467

Jakovljević, M. (2006). The modern psychopharmacotherapy, mind-body medicine and science of well-being. Body, brain, mind \& spirit: all for one, and one for all. Psychiatria Danubina, 18(3-4), 148-149.

Jette, A. M., Lachman, M., Giorgetti, M. M., Assmann, S. F., Harris, B. A., Levenson, C., ... Krebs, D. (1999). Exercise - it's never too late: the strong-for-life program. American Journal of Public Health, 89(1), 66-72.

Katschnig, H. (2006). Quality of life in mental disorders: Challenges for research and clinical practice. World Psychiatry, 3, 139-45.

Lahelma, E., Martikainen, P, Rahkonen, O., \& Silventoinen, K. (1999). Gender differences in ill health in Finland: patterns, magnitude and change. Social Science \& Medicine, 48, 7-19. https://doi.org/10.1016/ S0277-9536(98)00285-8

Loge, J. H., \& Kaasa, S. (1998). Short form 36 (SF36) health survey: Normative data from the general Norwegian population. Scandinavian Journal of Social Medicine. 26, 250-258. doi.org/10.1177/140349489802 60040401

Martisen, E.W. (2008). Physical activity in the prevention and treatment of anxiety and depression. Nordic Journal of Psychiatry, 62(47), 25-29. https://doi. org/10.1080/08039480802315640

Mason, O. J., \& Holt, R. (2012). Mental health and physical activity interventions: A review of the qualitative literature. Journal of Mental Health, 21(3), 274-284. https://doi.org/10.3109/09638237.2011.648344

Niels, L. (2004). Values reflected in the human development index. Social Indicators Research, 66(3), 283-293.

Reklaitiene, D., Karpaviciute, S., \& Pozeriene, J. (2010). Quality of life of people who are deaf and with hearing impairment. Special Education, 1(22), 8-16.

Revicki, D., Kleinman, L., \& Cella, D. (2014). A history of health-related quality of life outcomes in psychiatry. Dialogues in Clinical Neuroscience, 16, 127-135.

Roshanaei Moghaddam, B., Katon, W. J., \& Russo, J. (2009). The longitudinal effects of depression on physical activity. General Hospital Psychiatry, 31(4), 306-315. https://doi.org/10.1016/j.genhosppsych.2009.04.002 
Rugienè, R., Dadonienè, J., \& Venalis, A. (2005). Gyvenimo kokybès klausimyno adaptavimas, jo tinkamumo kontrolinei grupei ir reumatoidiniu artritu sergantiems ligoniams įvertinimas. Medicina, 41(3), 232-239.

Saxena, S., Van Ommeren, M., Tang, K. C., \& Armstrong, T. P. (2005). Mental health benefits of physical activity. Journal of Mental Health, 14(5), 445451. https://doi.org/10.1080/09638230500270776

Szende, A., \& Nemeth, R. (2003). Health-related quality of life of the Hungarian population. Orvosi Hetilap, 144, 1667-1674.

Vaez, M., Ekberg, K., \& Laflamme, L. (2004). Ratings of health and quality of life by young working people: Are there occupational or education-based differences? Work, 23, 193-198.

Wiles, N. J., Haase, A. M., Gallacher, J., Lawlor, D. A., \& Lewis, G. (2007). Physical activity and common mental disorder: Results from the Caerphilly study. American Journal of Epidemiology, 165(8), 946-954. https://doi. org/10.1093/aje/kwk070

World Health Organization. (2015). WHO definition of health. Retrieved from http://www.who.int/ about/ definition/en/print.html.

Wynaden, D., Barr, L., Omari, O., \& Fulton, A. (2012). Evaluation of service users' experiences of participating in an exercise programme at the Western Australian State Forensic Mental Health Services. International Journal of Mental Health Nursing, 21(3), 229-235. https://doi. org/10.1111/j.1447-0349.2011.00787.x

Xiang, Y. T., Chiu, H. F., \& Ungvari, G. S. (2010). Quality of life and mental health in Chinese culture. Current Opinion in Psychiatry, 23(1), 43-47. doi: 10.1097/YCO.0b013e328333d60f 